\title{
A DINÂMICA E OS FATORES ORGANIZACIONAIS PROPICIADORES À OCORRÊNCIA DO ASSÉDIO MORAL NO TRABALHO
}

\section{THE DYNAMIC AND THE ENABLING ORGANIZATIONAL FACTORS TO THE OCCURRENCE OF WORKPLACE BULLYING}

\section{Thiago Soares Nunes}

Doutorando em Administração pelo Programa de Pós-Graduação em Administração da Universidade Federal de Santa Catarina - UFSC

Pesquisador do Núcleo de Estudos do Trabalho e Constituição do Sujeito da Universidade Federal de Santa Catarina - NETCOS/UFSC

E-mail: adm.thiagosn@gmail.com (Brasil)

\section{Suzana da Rosa Tolfo}

Doutora em Administração pela Universidade Federal de Rio Grande do Sul - UFRGS

Professora do Programa de Graduação e Pós-Graduação em Psicologia e do Programa de PósGraduação em Administração da Universidade Federal de Santa Catarina - UFSC

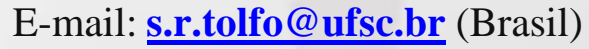




\title{
A DINÂMICA E OS FATORES ORGANIZACIONAIS PROPICIADORES À OCORRÊNCIA DO ASSÉDIO MORAL NO TRABALHO
}

\section{RESUMO}

Neste artigo é apresentada uma revisão da literatura sobre o assédio moral, com uma abordagem voltada para a Ciência da Administração e Psicologia Organizacional e do Trabalho. Considera-se que, no atual contexto, existem alguns fatores organizacionais propiciadores à ocorrência do assédio moral, e que são importantes de ser compreendidos pelos gestores. O assédio moral trata de um processo complexo que inclui a interação de aspectos interpessoais, sociais (grupais) e organizacionais. A abordagem aqui focada é a do assédio moral organizacional, cujo objetivo é atingir o trabalhador por meio de estratégias organizacionais de constrangimento com o objetivo de melhorar a produtividade. Ressalta-se que existem alguns fatores organizacionais que podem propiciar o assédio, como a mudança da natureza e da organização do trabalho, cultura e clima organizacional, assim como liderança. Buscaram-se subsídios conceituais explicativos do fenômeno nos modelos propostos, os quais demonstram a interação dos diversos aspectos supracitados que influenciam na ocorrência.

Palavras-chave: Assédio Moral no Trabalho; Assédio Moral Organizacional; Fatores Organizacionais Propiciadores ao Assédio Moral; Dinâmica do Assédio Moral.

\section{THE DYNAMIC AND THE ENABLING ORGANIZATIONAL FACTORS TO THE OCCURRENCE OF WORKPLACE BULLYING}

\begin{abstract}
This article presents a review of literature in workplace bullying, with an approach aimed at the scope of the Administration Science and the Work and Organizational Psychology. Studies demonstrate the existence of organizational factors that enable the occurrence of workplace bullying, which are important to be understood by managers. Workplace bullying is a complex process that includes the interaction among interpersonal, social (group), and organizational aspects. This study is focused on the organizational workplace bullying, whose aim is to achieve the worker through organizational strategies of embarrassment in order to improving the productivity. Furthermore, there are some key organizational factors that can facilitate workplace bullying, such as: changings in the nature of work, work organization, organizational culture and climate; as well as leadership. In order to achieve the objectives, explicative propositions were searched in specific literature, which demonstrates the interaction of the various aspects that influence the occurrence of workplace bullying.
\end{abstract}


Keywords: Workplace Bullying; Organizational Workplace Bullying; Enabling Organizational Factors for Workplace Bullying; Workplace Bullying Dynamic.

Revista de Gestão e Secretariado - GeSec, São Paulo, v. 4, n. 2, p 90-113, jul./dez. 2013. 


\section{INTRODUÇÃO}

A administração, vista como ciência, começou a se desenvolver durante a Revolução Industrial, no século XVIII, tendo como principais colaboradores Frederick Taylor, Henry Fayol e Max Weber. Todavia, as teorias administrativas desenvolveram-se no século XX, em decorrência da necessidade das grandes empresas (Ford, General Motors, Goodyear, General Eletric e Bell Telephone) que estavam surgindo. Naquele momento, o enfoque da administração estava na produção de bens para atender a um mercado crescente e aparentemente inesgotável (Tachizawa, Cruz Júnior e Rocha, 2006). Os primeiros pressupostos destacados pelos principais precursores da administração científica e clássica são similares e complementares, adotando uma abordagem presente nos dias atuais: como, por exemplo, criar uma organização que, de forma eficiente, atinja seus objetivos. Ou seja, pretendia-se aumentar a eficiência da produção aumentando a eficiência dos trabalhadores.

Ramos (1989) comenta que a maioria das organizações produtivas tem como referência a racionalidade instrumental, determinando assim, o seu padrão de funcionamento orientado pelas leis de mercado. Este processo da racionalidade instrumental como dimensão norteadora do padrão instituído das organizações, faz com que a racionalidade substantiva, importante para o processo de construção e desenvolvimento da identidade do profissional e sua autorrealização, tende a ser esquecida. As necessidades, interesses e sentimentos das pessoas ficam em segundo plano ou sequer são cogitadas devido ao foco exclusivo do enfoque técnico.

Consequentemente, a visão do homem visto apenas como uma peça de uma máquina não persiste muito tempo. Segundo Morgan (2009), o estudo da motivação humana repercutiu como uma crítica significativa para o modelo de organização da administração científica, de modo que este estilo de administrar procurava motivar os empregados por meio de dinheiro - deixando o desenvolvimento humano ao nível mais baixo da hierarquia das necessidades. Se, por um lado, com a escola das relações humanas há avanços no sentido de maior humanização no trabalho, por outro, há o surgimento do "homem reativo", que passa a ser visto como um ser mais complexo, cuja motivação é impulsionada por valores, sentimentos e atitudes com relação ao grupo no qual interage.

Como explicado, na teoria da administração científica o foco está nos processos de trabalho, já na teoria das relações humanas o foco está no indivíduo, seus comportamentos, satisfação e 
motivação. Deste modo, acreditava-se na correlação entre felicidade e produtividade, ou seja, ao conhecer a necessidade do funcionário é possível motivá-lo com a finalidade de que ele tenha maior eficiência no trabalho - e esta ainda é uma estratégia válida e adotada pelas organizações (Nunes, 2011; Nunes \& Tolfo, 2012a).

Ziemer (1996) defende que devido a uma visão mecanicista e racionalista, a organização criou uma sombra própria que engloba principalmente os aspectos subjetivos do comportamento humano, ou seja, a sombra é a distância do professado e o praticado.

A sombra organizacional "é constituída de características inaceitáveis que incluem todos os comportamentos, atitudes, valores, crenças e normas que não se coadunam com a imagem e a identidade que a organização almeja criar de si mesma” (Ziemer, 1996, p. 119). Ela pode ser compreendida por meio da metáfora do "icebergue organizacional". Esta analogia - estruturada por Selfridge e Sokolik em 1975 - trata da identificação e interação dos componentes visíveis e dos componentes invisíveis de uma organização, que formam, deste modo, um todo unitário e indivisível (Oliveira, 2008).

Embora os componentes que estão abaixo da linha d'água (objetivos, estrutura, tecnologia, e outros) geralmente não sejam reconhecidos/visíveis no cotidiano da organização, eles apresentam uma grande influência no seu funcionamento. A dimensão invisível do icebergue compreende aspectos latentes, que geralmente são negados ou negligenciados pela visão tradicional. Sina (2007) expõe que em algumas empresas há a prática deturpada dos valores. Como exemplo, onde se lê respeito, é praticada a falta de apreço pela dignidade humana e o uso elevado de expressões pejorativas para se referir a determinadas pessoas ou grupos de trabalho.

Muitas empresas têm explicitados seus virtuosos valores em cartazes dispostos bem à vista de todos. Tais valores geralmente são elencados de acordo com a cultura própria do lugar, dos colaboradores e de sua disposição em exercê-los. No entanto, muitas vezes ficam apenas confinados ao papel, tornando-se letras mortas, ou ainda, significam o contrário do descrito. De fato nenhuma organização ousaria emoldurar, para que todos vissem, a prática dos valores não virtuosos ou valores "encobertos" (Sina, 2007). A autora cita alguns exemplos: subir na carreira a qualquer preço; cobiçar a todo momento o cargo alheio e trabalhar para que o cargo fique vago; agir sem transparência com clientes e parceiros; pôr a perder o esforço de alguém na busca de resultados para tornar evidente que ele/ela não merece a função e o salário; e apresentar-se como opção para esse cargo quando estiver vago. "A sinalização para o uso desses artifícios vem do líder e de seus colaboradores diretos quando o que impera é a pressão em grau máximo” (Sina, 2007, p. 146). 
Para Lubit (2002, p. 73) “muitas organizações se concentram principalmente nos lucros em curto prazo, e dão pouca ou nenhuma atenção ao custo humano decorrente da forma como os gestores atingem resultados financeiros". Se os gestores apresentam um bom desempenho - leia-se resultado - a alta direção da organização possivelmente não leva em consideração as falhas do seu gestor em desenvolver os subordinados, incentivar o trabalho em equipe, dar apoio moral e tratar bem os outros (Lubit, 2002). No entanto, esses gestores são recompensados por atingirem as metas, independente do modo como a conseguiram.

Heloani (2005) traz uma interessante reflexão sobre um paradoxo atual, a conciliação de dois sujeitos historicamente desiguais: capital e trabalho. É evidente o discurso da cooperação e trabalho em equipe; há diversos trabalhos e palestras a respeito destes temas. Contudo, para o autor, tais elementos são antagônicos em sua base, pois, por um lado, há a necessidade de cooperação em equipe e, por outro, há a competição pela aquisição e manutenção de um posto de trabalho. A aceitação do "trabalho sujo" como forma de o trabalhador se manter no posto de trabalho, segundo metáfora de Dejours (2007) que explica a participação consciente do sujeito em atos injustos como um ato calculista. Participação esta justificada, sobretudo, para manter seu lugar, conservar seu cargo, sua posição, seu salário e não comprometer seu futuro na organização.

Em muitas organizações o indivíduo é incitado a participar de uma cultura organizacional, que objetiva o resultado acima de tudo, a utilizar-se de métodos, manipulações e atos para cumprir suas metas, não se importando com a execução de práticas violentas para tal fim.

As exigências de metas, a competitividade nas organizações, pressão por parte dos diretores, entre outras manifestações, provocam nos trabalhadores inseguranças e determinado grau de ansiedade que em determinadas circunstâncias influenciam na ocorrência de comportamentos violentos no ambiente de trabalho. A Organização Internacional do Trabalho (OIT), segundo Freitas (2007) alerta que a violência no ambiente de trabalho apresenta um crescimento exponencial em todo o mundo nas últimas décadas. Esta violência, muitas vezes, pode ser justificada pela questão do poder. Como mencionado, alguns indivíduos por medo de perder sua posição começam a praticar formas de violência com os demais colegas mediante o atropelamento da ética e da própria dignidade humana (Heloani, 2005; Dejours, 2007). Para os autores esta violência é algo intrínseco ao ser humano, assim como o amor, ódio, poder, submissão, orgulho, inveja e demais facetas da personalidade.

$\mathrm{O}$ abuso do poder, de forma repetida e sistematizada durante um período de tempo, constitui 
a principal característica do assédio moral, configurando a prática da perversidade no local de trabalho. Apesar de o assédio moral ser considerado uma violência tão antiga quanto o próprio trabalho, foi apenas nos últimos anos que o tema se tornou popular nas mídias e no ambiente acadêmico (Freitas, Heloani \& Barreto, 2008; Nunes \& Tolfo, 2012b). O alemão Heinz Leymann é considerado o precursor dos estudos empíricos sobre assédio moral, iniciados em 1980, quando pesquisou em diversas organizações na Suécia sobre o sofrimento no trabalho, chegando a resultados que o estimularam a ampliar em nível nacional as suas pesquisas (Einarsen, Hoel, Zapf e Cooper, 2003, 2005, 2011; Freitas et al., 2008). O objetivo dessas pesquisas era sensibilizar os assalariados, sindicatos, gestores, médicos e juristas para a gravidade da situação, incentivando-os, deste modo, ao combate e prevenção do assédio moral. Para Leymann (1990, 1996) o assédio moral (ou terror psicológico/psicoterror) envolve comunicação hostil e não ética, direcionada de um modo sistemático por um ou mais indivíduos para um indivíduo que, durante o assédio, é colocado em uma posição desamparada e indefesa e mantido nesta condição por meio de ações hostis.

A autora francesa Hirigoyen (2008), responsável pela popularização do tema em diversos países, inclusive no Brasil, define que o assédio moral pode ser caracterizado por repetidas e frequentes condutas abusivas expressas por meio da escrita, palavras e gestos que visam agredir psiquicamente e fisicamente o indivíduo. Nota-se que a definição desses autores é similar e complementar, assim como outras definições de autores (Nunes, 2011). Por ocorrer dentro do ambiente laboral, a organização cumpre um papel fundamental nesta violência se não tem políticas e práticas de prevenção e punições e, especialmente, se incentiva esta prática para um melhor desempenho produtivo - ou seja, a organização pode ser considerada corresponsável pela ocorrência desse tipo de violência.

Nesse sentido, este artigo tem como propósito apresentar uma revisão da literatura internacional e nacional sobre o assédio moral no trabalho - especificamente sobre os fatores organizacionais que atuam na incidência do assédio moral, e a própria dinâmica e complexidade do assédio - com o foco em uma abordagem voltada para o âmbito da Ciência da Administração. Para tanto, foi realizada uma pesquisa bibliográfica prioritariamente em periódicos científicos, buscando autores representativos na área que evidenciam aspectos organizacionais no âmbito do assédio moral tais como: Einarsen et al. (2003, 2005, 2011), Salin (2003a, 2003b), Vartia (2003) e Freitas et al. (2008). 


\section{ASSÉDIO MORAL NO TRABALHO}

Muitos ambientes organizacionais e práticas das empresas continuam com o mesmo pensamento do início das teorias administrativas, voltadas para aumentar a produtividade e lucratividade a qualquer custo (Nunes \& Tolfo, 2012a). Ou seja, a produtividade tem sido a norteadora das ações e práticas administrativas, e associada à atual competitividade, leva o indivíduo a trabalhar frequentemente no seu limite, sobretudo no nível emocional (Nunes, 2011). De acordo com Freitas et al. (2008) as organizações definem, de forma explícita ou implícita, por meio de sua cultura determinados padrões de relacionamento e estrutura (formal e informal), e principalmente os seus valores. "Quando consideramos o assédio moral uma questão organizacional, entendemos que algumas empresas negligenciem os aspectos desencadeadores desse fenômeno, ou seja, consideramos que o assédio moral ocorra não por que os dirigentes o desejem, mas porque eles se omitem" (Freitas et al., 2008, p. 38).

É inegável que o assédio moral é também um problema de nível organizacional, pois ocorre dentro do ambiente laboral. Assim, a organização torna-se corresponsável pela sua prática ou pela isenção de tais comportamentos e ações. Martiningo Filho (2007) afirma que o assédio moral organizacional é uma causa da ineficiência da organização, podendo provocar considerável queda na produtividade, apresentar um custo social em termos de indenizações e aposentadorias precoces, além de tratamentos psicológicos e médicos exigidos pelas vítimas. Gosdal, Soboll, Schatzmam e Eberle (2009, p. 37) definem o assédio moral organizacional como:

um conjunto de práticas reiteradas, inseridas nas estratégias e métodos de gestão, por meio de pressões, humilhações e constrangimentos, para que sejam alcançados determinados objetivos empresariais ou institucionais, relativos ao controle do trabalhador (aqui incluído o corpo, o comportamento e o tempo de trabalho), ou ao custo do trabalho, ou ao aumento de produtividade e resultados, ou à exclusão ou prejuízo de indivíduos ou grupos com fundamentos discriminatórios.

Esta distinção entre o assédio moral interpessoal e organizacional para Gosdal et al. (2009) consiste em dar maior evidência à dimensão coletiva do assédio que está inserida nas estratégias de gestão organizacional. Tal separação, sob o ponto de vista didático, pode demonstrar melhor a

Revista de Gestão e Secretariado - GeSec, São Paulo, v. 4, n. 2, p 90-113, jul./dez. 2013. 
ocorrência e características do fenômeno e dos aspectos envolvidos (agressor, vítima, organização, ambiente de trabalho, e outros). Já sob o ponto de vista prático, a separação entre interpessoal e organizacional não se faz necessária, pois o foco está no fenômeno em si.

A abordagem inicial dos estudos acerca do assédio moral procurava definir as características e criar um perfil tanto para a vítima quanto para o agressor (Nunes, 2011). Quando observadas as explicações para a ocorrência do assédio moral em um nível individual de análise, a personalidade da vítima e do agressor tendem a receber maior atenção. Zapf e Einarsen (2003) e Vartia (2003) relatam que os fatores individuais e a personalidade dos envolvidos (vítima e agressor) são aspectos importantes para análise da ocorrência do assédio moral, pois estes podem apresentar características e personalidades capazes de contribuir para o envolvimento em situações de assédio. Pesquisas desenvolvidas por Zapf e Einarsen (2003) demonstram que vítimas são descritas como cautelosas, sensíveis, quietas, ansiosas e inseguras, já os assediadores são descritos como autoconfiantes, impulsivos e geralmente agressivos.

É importante ressaltar que as contribuições iniciais do tema vieram quase que exclusivamente da Psicologia, a qual prestava maior atenção aos efeitos sobre o indivíduo e a sua saúde (Barreto, 2006; Bradaschia, 2007; Einarsen et al., 2011). Tal fato pode justificar o foco da abordagem inicial do tema com foco nos comportamentos do agressor e vítima, como forma de criar um padrão de comportamento para tal. Contudo, os avanços nos estudos permitiram verificar que o assédio moral é um fenômeno multidimensional e multidisciplinar, ou seja, também precisa ser compreendido com base nas perspectivas advindas de outras ciências como a Administração, Direito, Medicina e demais. Desse modo, a organização, palco da violência, foi inserida como um fator que influencia ou é influenciada por esta violência.

No assédio moral organizacional as perseguições, humilhações e pressões dirigidas a um ou mais trabalhadores têm como intuito servir de exemplo para os demais membros, de modo que estes alcancem as metas e objetivos estabelecidos pela organização de qualquer forma, ou seja, visa atingir o indivíduo por meio de estratégias organizacionais de constrangimento com o objetivo de melhorar a produtividade (Gosdal et al., 2009; Nunes, 2011). Fica evidente o predomínio da racionalidade instrumental, uma vez que o importante são os resultados finais e não o meio para alcançá-los. Corroborando com o apresentado anteriormente, Freitas et al. (2008, p. 38) afirmam que nas organizações “as pessoas se pautam mais pelo aspecto legal que pelo moral, porém, a convivência social prolongada não pode subsistir sem que a instância moral também exerça a sua parte no controle de comportamentos e de atitudes dos indivíduos”.

Revista de Gestão e Secretariado - GeSec, São Paulo, v. 4, n. 2, p 90-113, jul./dez. 2013. 
O assédio moral é um processo complexo e dinâmico, em que a ação e reação devem ser compreendidas dentro do contexto social onde ocorrem, doravante, os fatores situacionais podem aumentar a vulnerabilidade dos alvos e contribuir para sua reação ao comportamento hostil (Hoel \& Salin, 2003). A partir desta afirmação, a seguir serão apresentados alguns fatores organizacionais que antecedem o assédio moral organizacional. São eles: 1) mudança na natureza do trabalho; 2) organização do trabalho; 3) cultura e clima organizacional; e 4) liderança (Salin, 2003b; Hoel \& Salin, 2003).

Mudanças na economia global aumentaram a competição entre as organizações, assim para sobreviver neste ambiente econômico elas passam por processos de reestruturação e downsizing com intuito de cortar custos, provocando grande pressão entre os seus trabalhadores para com os resultados (Hoel \& Salin, 2003). Corroborando com o argumento acima, Martiningo Filho (2007, p. 16-17) expõe que:

\footnotetext{
Reestruturações e processos de downsizing levam à eliminação de posições na estrutura hierárquica da organização, comprimindo as oportunidades de promoção e aumentando a quantidade de trabalho e a competição interna e diminuindo a segurança no emprego. Esses fatores levam a um alto nível de pressão e de stress, facilitando o caminho para agressões e eliminação das ameaças (outros competidores).
}

Da mesma forma Freitas et al. (2008) relatam que nos processos de fusões, aquisições e reestruturações feitas sem um planejamento em relação aos afetados (pessoas e cargos), sem transparência e sem critérios claros de avaliação e negociação de demissões, geram rancor e ressentimentos que podem se manifestar de forma violenta. Os autores ainda ressaltam que nos casos das terceirizações podem gerar conflitos entre os funcionários efetivos e os terceirizados, criando assim um ambiente dividido, o que favorece para o início dos comportamentos e ações hostis. Para uma melhor visualização, Bradaschia (2007) apresenta uma figura sintetizando os fatores relacionados às mudanças dentro da organização, como pode ser visualizado a seguir.

Figura 1 - Fatores ligados às mudanças dentro das organizações.

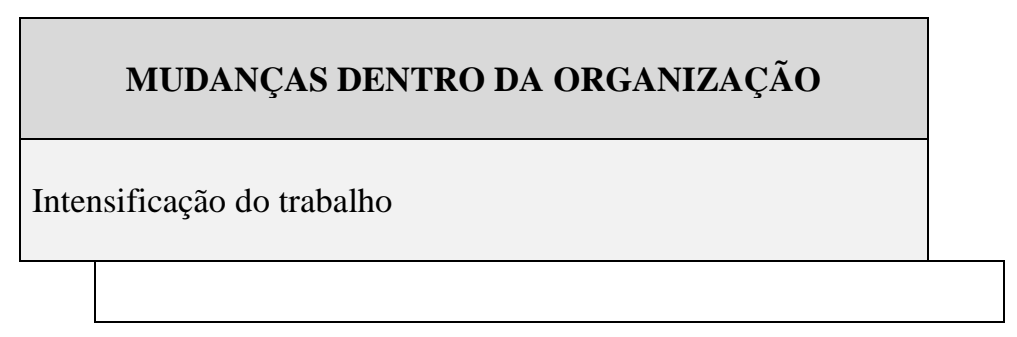

Revista de Gestão e Secretariado - GeSec, São Paulo, v. 4, n. 2, p 90-113, jul./dez. 2013. 


\begin{tabular}{|l|}
\hline Mudanças na composição do grupo de trabalho \\
\hline Downsizing e reestruturações \\
\hline Mudanças organizacionais \\
\hline Precariedade do emprego \\
\hline Aumento de estresse \\
\hline Queda de estabilidade de emprego \\
\hline Situação precária do trabalho \\
\hline
\end{tabular}

Fonte: adaptado de Bradaschia (2007).

Mudanças no status quo da organização, como mencionado por Hoel e Salin (2003), Martiningo Filho (2007), Freitas et al. (2008) podem provocar um sentimento de incerteza, dúvida e ocasionar pressão para que estes obtenham um desempenho elevado com intuito de não serem "dispensados".

No que se refere à organização do trabalho, a não satisfação e frustração com as más condições de trabalho, métodos e processos ineficientes e inadequados, demandas, estruturas e regras não claras, comunicação interna deficiente, são fatores que podem levar ao assédio moral (Hoel \& Salin, 2003; Salin, 2003b). Segundo Salin (2003b) dois aspectos relacionados ao trabalho estão fortemente associados a altos níveis de assédio e outras formas de comportamentos antissociais: a) o papel do conflito, que se refere às expectativas e demandas contraditórias do trabalho; e b) papel da ambiguidade, que se refere ao grau de incertezas quanto aos deveres e expectativas do trabalho. Leymann (1996) corrobora e explica que as deficiências no ambiente de trabalho, como regras e estruturas de comando não claras, tendem a proporcionar situações que podem conduzir ao conflito e ao assédio. A Figura 2, a seguir, apresenta alguns aspectos ligados à organização do trabalho. 
Figura 2 - Fatores ligados à organização do trabalho.

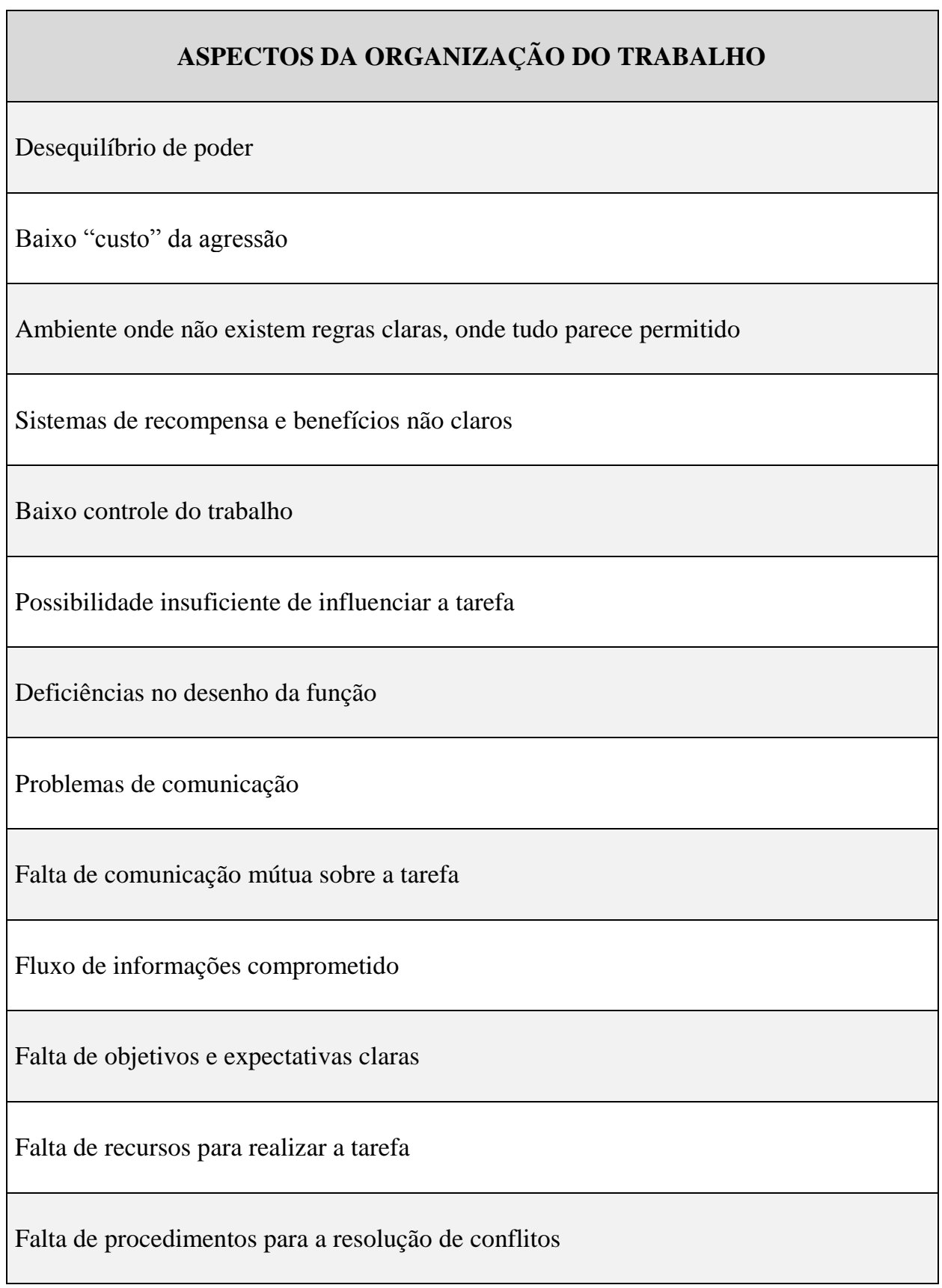


Fonte: adaptado de Bradaschia (2007).

Os aspectos físicos do ambiente de trabalho também podem agir como antecedentes para os comportamentos agressivos e ao assédio propriamente dito. Um ambiente com constante barulho/ruído, temperatura elevada/baixa ou um ambiente apertado de difícil mobilidade são fatores que foram associados ao aumento de comportamentos e atitudes de hostilidade (Hoel \& Salin, 2003).

Por outro lado, um dos fatores determinantes para a ocorrência do assédio moral é a cultura e o clima organizacional. A cultura organizacional se refere basicamente às normas, crenças e valores compartilhados pelos membros da organização. Entretanto, o assédio moral pode ser visto como uma parte da cultura, de modo que a ocorrência do assédio é aceita como uma forma para concretização da tarefa imposta (Salin, 2003b), o que vai ao encontro de uma organização que preze o constitucionalismo na relação com os empregados. Ao seguir esta racionalidade, na qual os fins justificam os meios, em organizações onde os assediadores têm conhecimento de que não há controle dos seus métodos de gestão e comportamento, pois estes conseguem realizar o trabalho, o assédio torna-se uma "ferramenta administrativa" muito eficiente para realizar o trabalho, sem se importar com as consequências para o assediado. Para Ziemer (1996, p. 125) "o fato de que a transmissão da cultura se dá basicamente de forma inconsciente e inquestionável explica, em parte, por que as empresas punem comportamentos desejados e recompensam aqueles indesejáveis".

Assim, em organizações onde os assediadores sabem que não serão punidos devido à falta de políticas para coibir, prevenir e punir o assédio, esta prática tende a se elevar cada vez mais em frequência e intensidade. Torna-se, pois, um modo de conseguir um desempenho satisfatório que pode levá-lo à obtenção de melhores condições na empresa. A seguir, baseado em Bradaschia (2007), apresenta-se uma figura com condicionantes da cultura e clima organizacional que podem influenciar o surgimento de situações de assédio moral.

Figura 3 - Aspectos relacionados à cultura e clima organizacional.

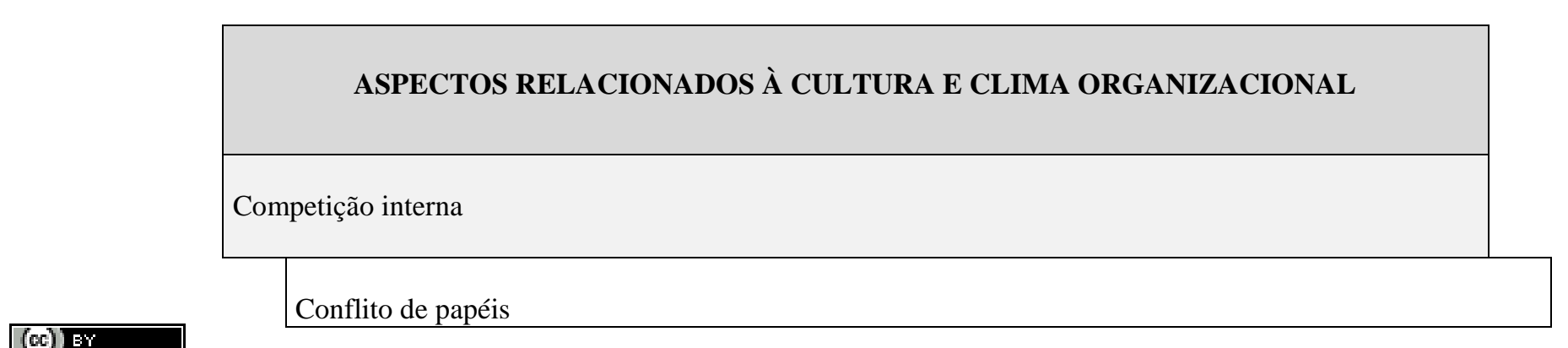

Revista de Gestão e Secretariado - GeSec, São Paulo, v. 4, n. 2, p 90-113, jul./dez. 2013. 
Insatisfação e frustração com o trabalho

Qualidade dos relacionamentos interpessoais dentro do grupo

Injustiça organizacional

Baixa qualidade do ambiente de trabalho

Baixos padrões morais no departamento

Conflito dentro da equipe

Piadas e humilhações como forma de testar novos membros

Fonte: adaptado de Bradaschia (2007).

Nota-se que algumas brincadeiras, insultos e pegadinhas são usadas como forma de testar novos membros da organização de modo a garantir o cumprimento das normas. Contudo, há um risco de estas "brincadeiras" se intensificarem e serem usadas pelo agressor como uma forma de perseguição, principalmente se ele identificar que o alvo não consegue "se defender" das ações ou não as encara como brincadeiras (Hoel \& Salin, 2003; Salin, 2003b).

No que diz respeito ao clima organizacional, existe uma significativa correlação entre o assédio moral e a baixa satisfação com o clima social, por exemplo: relações de cooperação fracas e um alto grau de inveja e competição interna (Einarsen et al., 2003). Similarmente, um clima competitivo e tenso pode provocar o surgimento de situações de assédio (Vartia, 2003; Salin, 2003b).

O clima organizacional nesses tempos de neoliberalismo revela-se cada vez mais individualista e competitivo, permeado por fofocas, críticas destrutivas e egoísmos, embustes e mentiras que contagiam os indivíduos e grupos, podendo desencadear um estado de ânimo marcado por tristes paixões, com inquietudes e incertezas (Freitas et al., 2008, p. 65). 
O último fator apontado por Hoel e Salin (2003) e Salin (2003a, 2003b) é a liderança. Segundo Ashforth (1995 como citado em Hoel \& Salin, 2003), pesquisas sobre o impacto de diferentes estilos de liderança em relação ao assédio moral é algo essencial. O autor ressalta que a maioria dos estudos sobre liderança foca na efetividade dos líderes, sendo que uma liderança negativa é vista como equivalente a uma liderança ineficaz, ou seja, pouca atenção foi dada aos aspectos destrutivos de tal liderança. A posição dos líderes frente às situações de assédio moral é algo fundamental de ser compreendido, sendo que este pode trabalhar para coibir e intervir em relação à ocorrência ou até mesmo promover e incentivar.

Bradaschia (2007) elencou alguns aspectos, com base na literatura, sobre o comportamento dos líderes e como estes podem influenciar na ocorrência de situações de assédio dentro das organizações.

Figura 4 - Aspectos relacionados ao comportamento dos líderes.

\begin{tabular}{|l|}
\hline \multicolumn{1}{|c|}{ ASPECTOS RELACIONADOS AO COMPORTAMENTO DOS LÍDERES } \\
\hline Gerência/superiores desinteressados \\
\hline Deficiências no comportamento dos líderes \\
\hline Fraqueza da autoridade hierárquica - poder paralelo \\
\hline Lideranças autocráticas \\
\hline Lideranças "liberais" (laissez-faire) \\
\hline Líderes abusivos
\end{tabular}

Fonte: adaptado de Bradaschia (2007).

É importante ressaltar que tanto uma liderança autocrática quanto uma liderança "liberal" (laissez-faire) podem prover solo fértil para episódios de assédio (Di Martino, Hoel \& Cooper, 2003; Skogstad, Matthiesen \& Einarsen, 2007). Por fim, lembra-se que outras questões relacionadas sobre os aspectos da liderança foram tratados em seções anteriores a esta aqui apresentada. Bem como, na seção a seguir é apresentado alguns fatores organizacionais que contribuem para coibição

Revista de Gestão e Secretariado - GeSec, São Paulo, v. 4, n. 2, p 90-113, jul./dez. 2013. 
ou ocorrência do assédio moral.

\subsection{DINÂMICA DO ASSÉDIO MORAL}

O assédio moral é um fenômeno social complexo caracterizado por sua multicasualidade, envolvendo aspectos psicológicos, interpessoais, organizacionais e ambientais. Dessa forma, serão abordados modelos conceituais explicativos que abrangerão os aspectos acima citados. Essas concepções são oriundas de Einarsen et al. (2003, 2005), Salin (2003a, 2003b) e Vartia (2003).

Einarsen et al. (2003) e Einarsen (2005) apresentam na Figura 5, a seguir, o modelo conceitual que identifica as principais variáveis inclusas nas pesquisas utilizadas para guiar e estruturar as ações e programas organizacionais de combate e prevenção do assédio.

Figura 5 - Modelo conceitual para o estudo e gestão do assédio moral no trabalho.

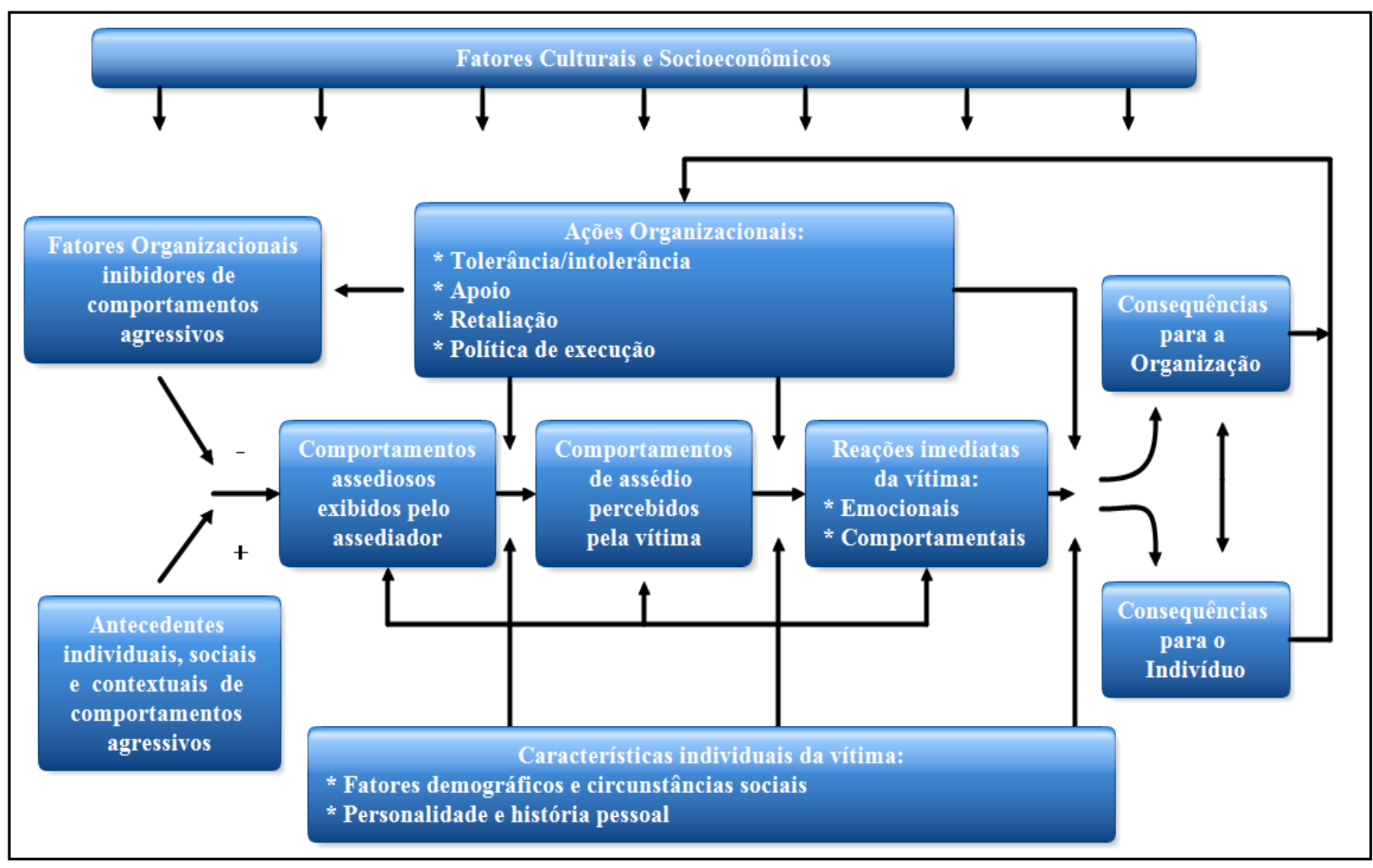

Fonte: adaptado de Einarsen et al. (2003, 2005) e Einarsen (2005).

Revista de Gestão e Secretariado - GeSec, São Paulo, v. 4, n. 2, p 90-113, jul./dez. 2013. 
Este modelo apresenta outro nível de explicação acerca do assédio; inclui o nível da sociedade, constituindo fatores culturais, históricos, legais e socioeconômicos. Einarsen (2005) ressalta a importância para quatro aspectos deste modelo: a) distingue entre a natureza e as causas dos comportamentos de assédio como é exibido pelo suposto agressor, e a percepção que a vítima tem da natureza e causas desses comportamentos; b) distingue entre a percepção da exposição dos comportamentos de assédio e a reação desses tipos de comportamentos; c) focaliza o impacto da organização em relação aos comportamentos dos supostos assediadores e a percepção e reação dos alvos; d) mostra que a personalidade do alvo é capaz de afetar como o comportamento do assediador é percebido e como eles reagem.

Este modelo conceitual define que a reação do alvo em relação ao assédio e a forma como a organização reage podem alterar as características pessoais do assediado (por exemplo, formas de reação e o comportamento). O modelo propõe que o assédio moral nasce de uma combinação da cultura organizacional que permite ou até recompensa este tipo de comportamento, além de fatores situacionais e pessoais (estresse, conflitos ou personalidade agressiva) (Einarsen et al., 2003, 2005). Os autores reforçam que o assédio moral pode ser resultante da combinação entre fatores que predispõem ao assédio (fatores pessoais e situacionais) e a ausência de fatores inibidores da organização em relação aos comportamentos agressivos. Brodsky (1976 como citado em Einarsen, 2005) assegura que embora a vítima e o agressor possam apresentar distúrbios de personalidade, o assédio acontecerá somente se a cultura organizacional permitir ou recompensar este tipo de mau comportamento (Freitas, 2001; Freitas et al., 2008).

Os fatores pessoais podem não ser relevantes como a causa para o comportamento do agressor; todavia, são importantes quando analisada a vulnerabilidade da vítima frente à persistência do comportamento agressivo. Os fatores organizacionais são fundamentais por interferir na percepção e reação da vítima em situações nas quais existe a ocorrência do assédio. Os fatores organizacionais quando bem estruturados e aplicados são importantes, pois podem inibir o comportamento agressivo e reduzir a ansiedade do assediado gerada por estes comportamentos, de modo que os seus direitos possam ser reivindicados (Einarsen et al., 2003; Einarsen, 2005).

Os fatores culturais e socioeconômicos tendem a afetar todas as variáveis neste modelo. As diferentes culturas nacionais ou locais podem definir o modo como o conflito no âmbito do trabalho é controlado ou a tolerância do comportamento agressivo. As diferenças nos sistemas legais estão relacionadas a quanto esforço uma organização está disposta a alocar na adoção de medidas preventivas e também quanto de proteção à vítima pode esperar da organização (Einarsen, 2005).

Em relação aos fatores socioeconômicos, o mercado de trabalho afeta a mobilidade da vítima

Revista de Gestão e Secretariado - GeSec, São Paulo, v. 4, n. 2, p 90-113, jul./dez. 2013. 
na troca de emprego como forma de fugir do assédio, enquanto a situação econômica e a competitividade influenciam na forma como os trabalhadores são tratados e quanta atenção a organização está disposta a pagar por este "pequeno conflito" (Einarsen, 2005). Por fim, o modelo conceitual de Einarsen et al. $(2003,2005)$ aborda a dinâmica do assédio moral incluindo um fator de extrema importância nos estudos posteriores, a organização como um agente inibidor ou promovedor dos comportamentos hostis.

Foi apresentado, anteriormente, o modelo conceitual do assédio proposto por Einarsen et al. (2003, 2005). Neste modelo foi possível identificar os antecedentes e os resultados do assédio, além dos diferentes níveis dos fatores que o compreendem (individual, organizacional e social). Salin (2003b) aperfeiçoou o modelo destes autores atribuindo significativas modificações nele. As modificações estão nos fatores que antecedem ao assédio, a inclusão da "Estrutura de poder na sociedade", além dos “Fatores organizacionais propiciadores, motivadores e precipitadores".

Figura 6 - Modelo conceitual revisado.

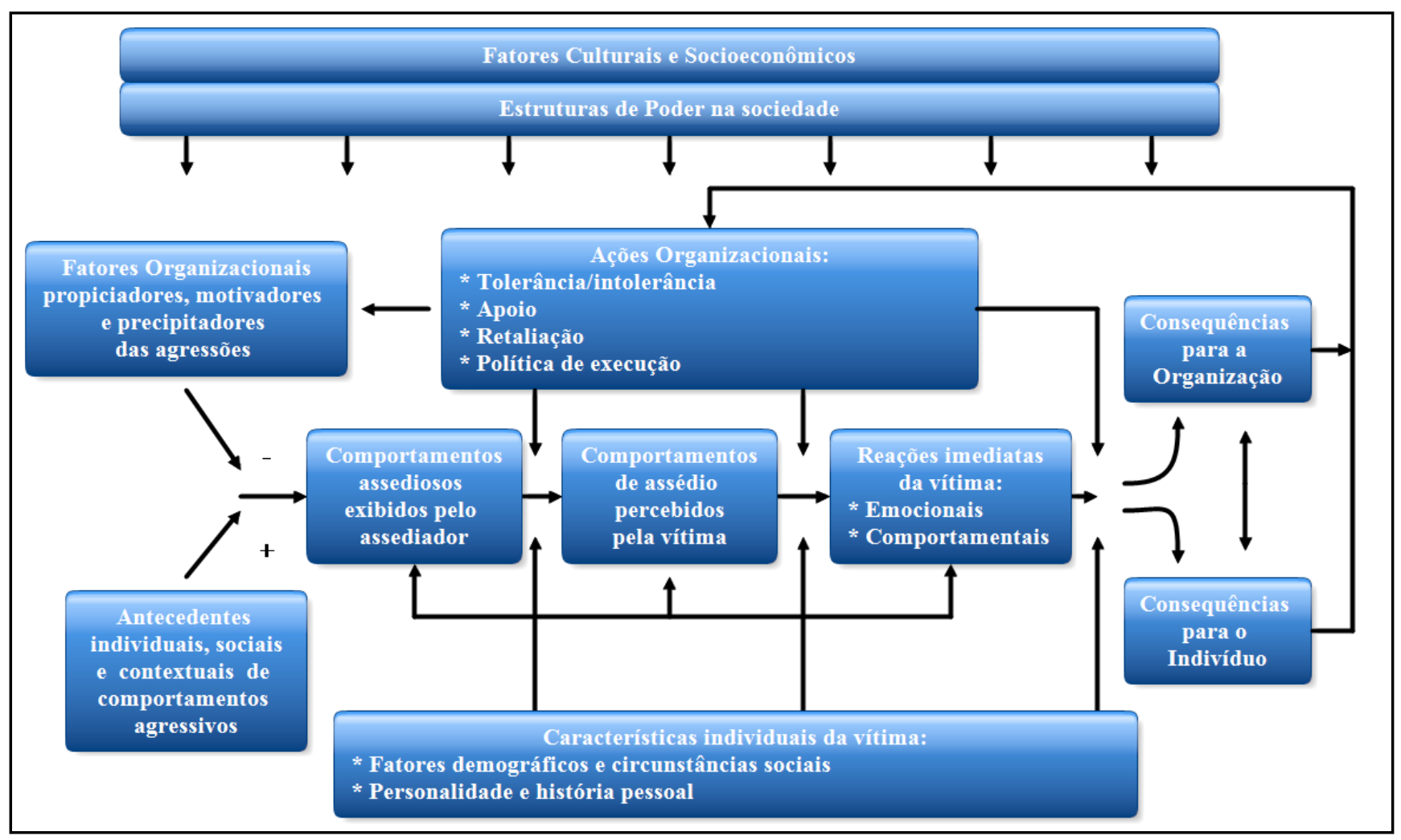

Fonte: adaptado Salin (2003b).

Revista de Gestão e Secretariado - GeSec, São Paulo, v. 4, n. 2, p 90-113, jul./dez. 2013. 
Salin (2003a, 2003b) apresenta um modelo que descreve os fatores que antecedem o assédio: Estruturas e processos propiciadores, estruturas e processos motivadores, e processos precipitadores (Figura 7).

Figura 7 - Estruturas e processos propiciadores, motivadores e precipitadores.

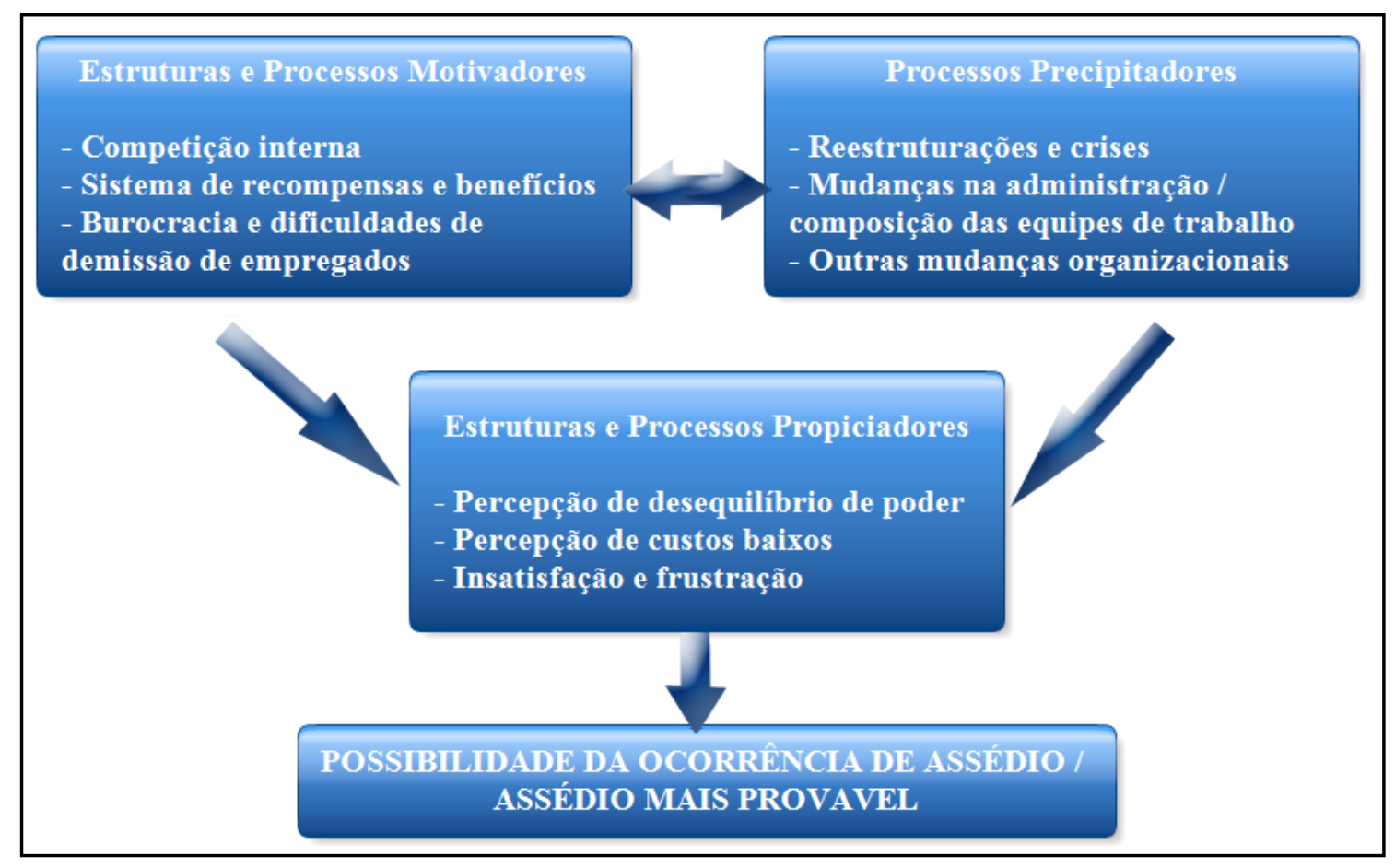

Fonte: adaptado Salin (2003a, 2003b).

A Figura 7 demonstra que o assédio pode ser compreendido como o resultado da interação entre três grupos (estruturas e processos motivadores; processos precipitadores; e estruturas e processos propiciadores), ou pelo menos dois deles. Boddewyn (1985 como citado em Salin, 2003a) argumenta que uma situação não acontece se ela não for possível, benéfica ou desejada. De fato as condições elencadas podem não levar ao assédio, mas agem como fatores propiciadores se no ambiente já houver uma motivação ou desejo. Os fatores motivadores e precipitadores não 
resultam no assédio se as condições não estiverem favoráveis; todavia, melhor atenção deve ser dada aos fatores propiciadores, que agem simultaneamente como base e filtro nas situações (Salin, 2003a).

Os fatores propiciadores podem provocar solo fértil para as práticas do assédio moral. Esses fatores incluem a percepção de desequilíbrio de poder (por exemplo, a diferença de poder formal), percepção de baixo custo (por exemplo, liderança fraca, permissiva ou inadequada, culturas organizacionais permissivas ou rígidas), e a insatisfação e frustração (por exemplo, a questão do conflito e ambiguidade dos papéis, falta de clareza, estresse e sobrecarga de trabalho). Quando há estruturas e processos motivadores e/ou precipitadores presentes, a existência ou ausência de estruturas e processos propiciadores na organização pode afetar a ocorrência do assédio moral (Salin, 2003a, 2003b).

As estruturas e processos motivadores consistem no grupo dos incentivos. Existem determinadas circunstâncias em que os empregados são recompensados por assediarem outros no ambiente de trabalho, conforme já mencionado. Os fatores motivacionais incluem alta competição interna, políticas de gestão e sistemas de recompensas que beneficiam os agressores e promovem a "eliminação" de colegas e subordinados e a retirada de "obstáculos" do caminho. Por exemplo, se uma organização promove um empregado que manipulou e assediou um colega, isto serve de “incentivo" para que outros possam fazer o mesmo (Salin, 2003a). O sistema de recompensas pode encorajar supervisores a "se livrarem" de empregados com alto ou baixo desempenho, de modo que este empregado pode ser visto como rival e ameaça devido ao seu talento/desempenho. Caso o desempenho do supervisor seja baseado nos seus subordinados, empregados com baixo desempenho são obstáculos para uma boa avaliação (Salin, 2003a). Este grupo apresenta uma perspectiva política e identifica que, em determinadas circunstâncias, o assédio a um indivíduo é algo "racional" a ser feito (Salin, 2003b).

Os processos precipitadores são vistos como gatilhos para o assédio moral e envolvem mudanças no status quo da organização, como o downsizing, reestruturação, reengenharia, fusão, outras mudanças organizacionais e mudanças na administração e na composição das equipes de trabalho. A reestruturação e o downsizing levam à eliminação de papéis e posição, comprimindo oportunidades de promoção, aumento da carga de trabalho e competição interna - o que provoca incertezas, pressão e aumento do estresse, levando determinados empregados a comportamentos hostis frente a outros para assim se sobressair no ambiente de trabalho. Por sua vez, as mudanças na 
administração e na composição das equipes de trabalho, refletem que a diversidade dos trabalhadores em termos de idade, sexo e etnia podem provocar a incidência de violência no ambiente de trabalho, motivada pela intolerância e discriminação (Nunes, 2011). O modelo apresentado de Salin (2003a, 2003b) está focado nos fatores no ambiente de trabalho, contribuindo para o modelo de Einarsen et al. (2003, 2005) e Einarsen (2005). Salin (2003a) afirma que seu modelo conceitual não deve ser visto como um modelo acabado, mas como uma tentativa preliminar de promover uma visualização mais ampla dos mecanismos internos das organizações que podem gerar a ocorrência do assédio.

O termo assédio moral, conforme Vartia (2003), tem sido utilizado em situações nas quais um ou mais indivíduos são alvos de repetidos e persistentes atos negativos por um ou mais colegas de menos nível, supervisores ou subordinados, e são incapazes de lidar com a situação. A autora apresenta na Figura 8 um modelo teórico conceitual, que contém o ambiente de trabalho, características individuais da vítima e do assediador, e processos grupais que são considerados como fatores potenciais na contribuição para a ocorrência dos casos de assédio.

Figura 8 - Modelo conceitual de Maarit Vartia.

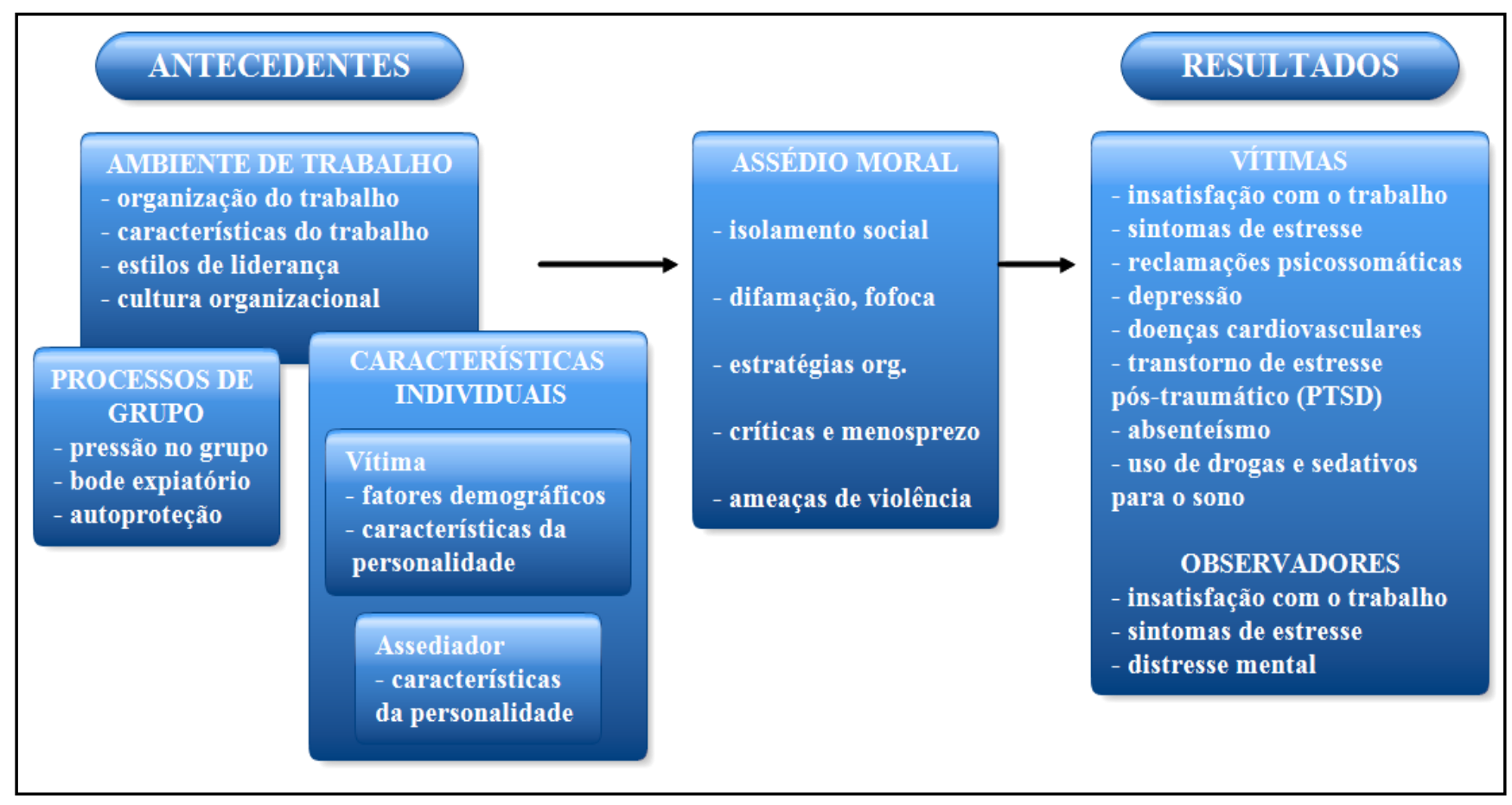

Fonte: adaptado Vartia (2003).

Revista de Gestão e Secretariado - GeSec, São Paulo, v. 4, n. 2, p 90-113, jul./dez. 2013. 
As hipotéticas consequências incluem a diminuição da satisfação do emprego, aumento dos sintomas de estresse e aumento do risco às doenças relacionadas ao estresse como a depressão e doenças cardiovasculares, transtorno de estresse pós-traumático (PTSD) e absenteísmo (Vartia, 2003). Como visualizado na Figura 8, as consequências advindas do assédio não se restringem apenas para as vítimas, mas pode afetar outros. O modelo de Vartia de forma geral está contido no apresentado por Einarsen et al. (2003, 2005) e Salin (2003a, 2003b) - assim este modelo não será detalhado como os outros apresentados.

A apresentação dos modelos conceituais do assédio moral demonstra a relação e combinação de diversos fatores que influenciam na ocorrência deste fenômeno ou na sua inibição. O modelo de Einarsen et al. $(2003,2005)$ apresenta como foco o indivíduo assediado, o assediador e a organização; já o modelo de Salin (2003a, 2003b) apresenta uma maior discussão da questão dos fatores propiciadores, motivadores e precipitadores do assédio moral nas organizações. Por outro lado, o modelo de Vartia (2003) demonstra uma lista de consequências que vítimas de casos de assédio e observadores podem sofrer.

\section{CONSIDERAÇÕES FINAIS}

O assédio moral é caracterizado por condutas frequentes e repetitivas que atentam contra a dignidade do trabalhador e que podem ser caracterizadas por ocorrências de deterioração proposital das condições de trabalho, isolamento e recusa de comunicação, atentado contra a dignidade e violência verbal, física ou sexual decorrentes de interações no trabalho. Embora se expresse nas relações interpessoais, o assédio não pode ser caracterizado somente como interpessoal, uma vez que vem se identificando situações de assédio nas quais os gestores da organização não inibem as ocorrências ou até mesmo as incentivam como forma de promover melhores desempenhos.

O assédio moral organizacional representa, então, um conjunto de práticas representativo da extrapolação da lógica da racionalidade instrumental, funcionalista, na qual os fins justificam os meios. Se a cultura organizacional não está baseada ou há dissonâncias entre o expresso e o praticado quanto a valores como justiça, constitucionalismo, respeito a normas e regras encontra-se aí um ambiente propício ao assédio.

Finalmente, ao se analisar os três modelos apresentados, que abordam o estudo e gestão do 
assédio moral no trabalho (Einarsen et al., 2003, 2005; Einarsen, 2005), as estruturas e processos propiciadores, motivadores e precipitadores (Salin, 2003a, 2003b) e antecedentes e resultados do assédio moral (Vartia, 2003) verifica-se que eles trazem importantes contribuições para que os administradores possam identificar múltiplas variáveis que propiciam a ocorrência do assédio moral nas organizações, bem como prevenir e coibir a sua ocorrência.

\section{REFERÊNCIAS}

Barreto, M. M. S. (2006). Violência, saúde e trabalho: uma jornada de humilhações. São Paulo: Educ.

Bradaschia, C. A. (2007). Assédio moral no trabalho: a sistematização dos estudos sobre um campo em construção. Dissertação (Mestrado em Administração de Empresas) - Programa de PósGraduação em Administração de Empresas, Fundação Getúlio Vargas, São Paulo, Brasil.

Dejours, C. (2007). A banalização da injustiça social. 7a ed. Rio de Janeiro: FGV.

Di Martino, V.; Hoel, H. \& Cooper, C. L. (2003). Preventing violence and Harassment in the workplace. Dublin: European Foundation for the Improvement of Living and Working Conditions.

Einarsen, S. (2005). The nature, causes and consequences of bullying at work: The Norwegian experience. Pistes, 7(3), pp. 1-14.

Einarsen, S.; Hoel, H.; Zapf, D. \& Cooper, C. L. (2011). The concept of bullying and harassment at work: the European tradition. In: Idem (orgs.). Bullying and harassment in the workplace: Developments in theory, research, and practice. London: Taylor \& Francis, pp. 3-39.

Einarsen, S.; Hoel, H.; Zapf, D. \& Cooper, C. L. (2003). The concept of bullying at work: the European tradition. In: Idem (orgs.). Bullying and emotional abuse in the workplace: International perspectives in research and practice. London: Taylor \& Francis, pp. 3-30.

Revista de Gestão e Secretariado - GeSec, São Paulo, v. 4, n. 2, p 90-113, jul./dez. 2013. 
Einarsen, S.; Hoel, H.; Zapf, D. \& Cooper, C. L. (2005). Workplace Bullying: individual pathology or organizational culture? In Bowie, V.; Fischer B. S. \& Cooper C. L. (orgs.). Workplace violence: issues, trends, strategies. Devon: Willian Publishing, pp. 229-247.

Freitas, M. E. (2001). Assédio moral e assédio sexual: faces do poder perverso nas organizações. Revista de Administração de Empresas. São Paulo: FGV, 41 (2), pp. 8-19.

Freitas, M. E. (2007). Cultura organizacional: evolução e crítica. São Paulo: Thomson Learning.

Freitas, M. E.; Heloani, J. R. \& Barreto, M. M. S. (2008). Assédio moral no trabalho. São Paulo: Cengage Learning.

Gosdal, T. C.; Soboll, L. A.; Schatzmam, M. \& Eberle, A. D. (2009). Assédio moral organizacional: esclarecimentos conceituais e repercussões. In: Gosdal, T. C. \& Soboll, L. A. (orgs.). Assédio moral interpessoal e organizacional: Um enfoque interdisciplinar. São Paulo: LTr, pp. 33-41.

Heloani, J. R. (2005). Assédio moral: a dignidade violada. Aletheia, 22, pp. 101-108.

Hirigoyen, M.-F. (2008). Assédio moral: a violência perversa no cotidiano. Rio de Janeiro: Bertrand Brasil.

Hoel, H. \& Salin, D. (2003). Organisational antecedents of workplace bullying. In: Einarsen, S.; Hoel, H.; Zapf D. \& Cooper C. L. (orgs). Bullying and emotional abuse in the workplace: International perspectives in research and practice. London: Taylor \& Francis, pp. 203-218.

Leymann, H. (1990). Mobbing and Psychological Terror at Workplaces. Violence and Victims, 5(2), pp. 119-126.

Leymann, H. (1996). The Content and Development of Mobbing at Work. European Journal of Work and Organizational Psychology, 5(2), pp. 165-184.

Lubit, R. (2002). O impacto dos gestores narcisistas nas organizações. Revista de Administração de Empresas. São Paulo, 42(3), pp. 66-77.

Martiningo Filho, A. (2007). Assédio moral e gestão de pessoas: Uma análise do assédio moral no trabalho e o papel da área de gestão de pessoas. Dissertação (Mestrado em Administração) Programa de Pós-Graduação em Administração, Universidade de Brasília, Brasília, Brasil.

Morgan, G. (2009). Imagens da organização. São Paulo (SP): Atlas. 
Nunes, T. S. (2011). Assédio moral no trabalho: o contexto dos servidores da Universidade Federal de Santa Catarina. Dissertação (Mestrado em Administração) - Programa de Pós-Graduação em Administração, Universidade Federal de Santa Catarina, Florianópolis, Brasil.

Nunes, T. S. \& Tolfo, S. R. (2012a). Políticas y prácticas de prevención y combate al acoso moral en una universidad brasileña. Salud de los Trabajadores, 20(1), pp. 61-73.

Nunes, T. S. \& Tolfo, S. R. (2012b). Prevenção e desenvolvimento de uma política anti-assédio moral no trabalho. Anais do XXXVI Encontro da ANPAD. Rio de Janeiro, Brasil.

Oliveira, D. P. R. (2008). Teoria geral da administração: uma abordagem prática. São Paulo: Atlas.

Ramos, A. G. (1989). A nova ciência das organizações: uma reconceituação da riqueza das nações. 2a ed. Rio de Janeiro: Fundação Getúlio Vargas.

Salin, D. (2003a). Ways of explaining workplace bullying: a review of enabling, motivating and precipitating structures and processes in the work environment. Human Relations, 56, pp. 1.2131.232.

Salin, D. (2003b). Workplace bullying among business professionals: Prevalence, organisational antecedents and gender differences. Doctoral dissertation. Research Reports, Serie A, no 117. Helsinki: Swedish School of Economics and Business Administration.

Selfridge, R. J. \& Sokolik, S. L. (1975). A comprehensive view of organizational management. MSU Business Topics, 23(1), pp. 46-61.

Sina, A. (2007). A outra face do poder. São Paulo: Saraiva.

Skogstad, A.; Matthiesen, S. B. \& Einarsen, S. (2007). Organizational changes: A precursor of bullying at work?. International Journal of Organization Theory and Behavior, 10, pp. 58-94.

Tachizawa, T.; Cruz Júnior, J. B. \& Rocha, J. A. O. (2006). Gestão de negócios: visões e dimensões empresariais da organização. São Paulo: Atlas.

Vartia, M. (2003). Workplace bullying: A study on the work environment. well-being and health. Doctoral Dissertation. People and Work Research Reports 56. Helsinki: Finnish Institute of Occupational Health.

Zapf, D. \& Einarsen, S. (2003). Individual antecedents of bullying: victims and perpetrators. In: Einarsen, H.; Hoel, D.; Zapf D. \& Cooper, C. L. (orgs.). Bullying and emotional abuse in the workplace: International perspectives in research and practice. London: Taylor \& Francis, pp. 165-184. 
Ziemer, R. (1996). Mitos organizacionais: o poder invisível na vida das empresas. São Paulo: Atlas.

Revista de Gestão e Secretariado - GeSec, São Paulo, v. 4, n. 2, p 90-113, jul./dez. 2013. 